\title{
Análise de dados sobre postagens e documentos veiculados em Serviços de Redes Sociais On-line para informação sobre a covid-19
}

\author{
Data analysis of posts and documents about covid-19 in Online Social \\ Network Services
}

\section{Análisis de datos en postes y documentos publicados en Servicios de Red Social en Línea para información sobre covid-19}

Fernando de Assis Rodrigues ${ }^{1, a}$

deassis@ufpa.br| https://orcid.org/o0oo-0001-9634-1202

Jocivaldo Pereira Tavares ${ }^{1, b}$

2004tavarescbm@gmail.com| https://orcid.org/o000-0002-7251-6036

\footnotetext{
${ }^{1}$ Universidade Federal do Pará, Instituto de Ciências Sociais Aplicadas. Belém, PA, Brasil.

a Doutorado em Ciência da Informação pela Universidade Estadual Paulista.

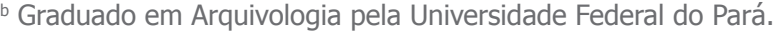

\section{RESUMO}

O objetivo foi analisar as postagens relacionadas à covid-19 em Serviços de Redes Sociais On-line por parte do Corpo de Bombeiros Militares, especialmente o caráter informativo desta instituição, com o propósito de identificar a relação entre postagens e documentos oficiais. Como procedimentos metodológicos foram delimitadas as seguintes ações: coletar os dados das postagens; analisar os dados, incluindo o cálculo de representatividade de postagens com suporte de documentos, os serviços mais utilizados e os períodos das postagens; verificar os termos de classificação; e realizar a análise dos documentos oficiais. A amostra foi delimitada ao Corpo de Bombeiros Militar dos estados do Pará, do Ceará, de São Paulo, de Santa Catarina e de Goiás - no Facebook, no Instagram e no Twitter. Os resultados apontam tempestividade na publicação de conteúdos nesses serviços nos primeiros dias. As publicações foram marcadas com termos da temática e do georreferenciamento. Identificou-se um baixo percentual de publicações ligadas a documentos oficiais: 5,05\% do total analisado. Destacam-se o Instagram, com maior veiculação, e a atuação nos estados de Goiás, Santa Catarina e Pará.

Palavras-chave: Serviços de Redes Sociais On-line; Corpo de Bombeiros Militar; Covid-19; Arquivologia; Documento. 


\section{ABSTRACT}

The objective was to analyze the posts on Online Social Network Services by the Military Firefighters Corps related to covid-19, especially the informative character of the institution, to identify the relationship between posts and official documents. As methodological procedures, the following actions were defined: collect data from the posts; analyze the data including the calculation of representativeness of posts supported by documents, most used services and post periods; check classification terms; and perform the analysis of official documents. The sample was limited to the Military Fire Brigades of the states of Pará, Ceará, São Paulo, Santa Catarina and Goiás on Facebook, Instagram and Twitter. The results show timeliness in the publication of content in these services in the early days. The publications were marked with terms of the theme and georeferencing. It was identified a low percentage of publications linked to official documents, $5.05 \%$ of the publications. Instagram stands out, with the greatest coverage, and the actions taken by the states of Goiás, Santa Catarina, and Pará.

Keywords: Online social networks services; Military Firefighter Corps; Covid-19; Archival science; Document.

\section{RESUMEN}

El objetivo fue analizar las publicaciones en los los Servicios de Redes Sociales en Línea de los Cuerpos de Bomberos Militares relacionadas con el covid-19, especialmente el carácter informativo de esta entidad, con el fin de identificar la relación entre las publicaciones y los documentos oficiales. Como procedimientos metodológicos se definieron las siguientes acciones: recolección de datos de las publicaciones; análisis de los datos, incluido el cálculo de la representatividad de las publicaciones respaldados por documentos, servicios y periodos de publicación más utilizados; consulta a los términos de clasificación; y la análisis de documentos oficiales. La muestra se limitó a los Bomberos Militares de los estados de Pará, Ceará, São Paulo, Santa Catarina y Goiás en Facebook, Instagram y Twitter. Los resultados muestran la puntualidad en la publicación de contenidos en estos servicios en los primeros días. Las publicaciones fueron marcadas con términos de la temática y georreferenciación. Se identificó un bajo porcentaje de publicaciones vinculadas a documentos oficiales: 5,05\% del total analizado. Se destacan Instagram, con la mayor cobertura, y la actuación de los estados de Goiás, Santa Catarina y Pará.

Palabras-clave: Servicios de redes sociales en línea; Cuerpos de Bomberos Militares; Covid-19; Archivología; Documento.

Contribuição dos autores:

Concepção e desenho do estudo: Fernando de Assis Rodrigues.

Aquisição, análise ou interpretação dos dados: Fernando de Assis Rodrigues e Jocivaldo Pereira Tavares.

Redação do manuscrito: Fernando de Assis Rodrigues e Jocivaldo Pereira Tavares.

Revisão crítica do conteúdo intelectual: Fernando de Assis Rodrigues.

Declaração de conflito de interesses: não há.

Fontes de financiamento: não houve.

Considerações éticas: não há.

Agradecimentos/Contribuições adicionais: não há.

Histórico do artigo: submetido: 25 ago. 2021 | aceito: 16 nov. 2021 | publicado: 25 fev. 2022.

Apresentação anterior: não houve.

Licença CC BY-NC atribuição não comercial. Com essa licença é permitido acessar, baixar (download), copiar, imprimir, compartilhar, reutilizar e distribuir os artigos, desde que para uso não comercial e com a citação da fonte, conferindo os devidos créditos de autoria e menção à Reciis. Nesses casos, nenhuma permissão é necessária por parte dos autores ou dos editores. 


\section{INTRODUÇÃO}

Com a evolução das Tecnologias de Informação e Comunicação (TIC), especialmente a partir da década de 2000, é possível observar um aumento na demanda de informações produzidas e recebidas por pessoas, empresas, órgãos públicos e demais entidades da sociedade. Essas informações são difundidas em alta velocidade e em abundância por compartilhamentos de usuários de Redes Sociais On-line (RSO).

As RSO têm a sua importância para a sociedade, apesar de maximizarem problemas já existentes, tais como: o bullying, o stalking e os aspectos relacionados à privacidade (BOYD, 2008; TEIXEIRA et al., 2018). Nesse contexto, nem tudo o que é mencionado e apresentado nas RSO é passível de verificação. Por conta da pandemia de covid-19, torna-se potencialmente perigosa a divulgação de informações ou notícias falsas (fake news) sobre o tema - o que pode ser fator-chave na condição de saúde dos cidadãos.

Pesquisas sobre notícias falsas já fazem parte da Arquivologia e da Ciência da Informação, nas quais o tema se insere a partir das investigações do fenômeno da desinformação e da sua relação com o tema da pós-verdade (FURTADO, BELLUZZO, 2018). Nesse contexto, devido ao fluxo considerável de informações veiculadas nas RSO, deve-se considerar o papel dessas áreas do conhecimento no processo de compreensão e de percepção do que é ou não é um processo de informação ao cidadão.

Os usuários dos Serviços de Redes Sociais On-line (SRSO), tais como o Facebook, o Instagram e o Twitter, podem se informar por conteúdos veiculados, especialmente quanto à situação de enfermidade, clicando em uma imagem, em um vídeo ou em um texto que contenham informações sobre a covid-19. Todavia, destaca-se a participação dos órgãos oficiais de Estado nos SRSO, de esfera estadual, municipal ou federal. As contas oficiais dessas entidades nos SRSO são relevantes, pois são as entidades que, em tese, podem dar a credibilidade e a segurança devidas sobre as informações.

Nesse processo de troca de mensagens e no fluxo de informações veiculadas nos SRSO, a velocidade com que as informações são publicadas nem sempre apresenta a possibilidade de uma janela de tempo adequada para a checagem da veracidade do conteúdo da informação. É relevante destacar que, após publicada a mensagem, não há condições de controlar o compartilhamento dessas informações, pois os SRSO são elaborados para facilitar não só o compartilhamento, como a participação e o engajamento de seus usuários aos conteúdos.

Para Sastre, Oliveira e Belda (2018), ainda são incipientes os estudos relacionados à complexidade do processo de tomada de decisão do usuário ao compartilhar ou não uma informação, especialmente acerca da identificação da mensagem, se o conteúdo é factual ou não. Contudo, deve-se pensar em um esforço para possibilitar meios para identificar tais mensagens nos SRSO e, nesse sentido, destaca-se o papel importante que os perfis oficiais das instituições governamentais têm nesses serviços, sobretudo em momentos de crise na saúde global ${ }^{1}$, universo de pesquisa deste estudo.

Em um sentido jurídico, é interessante uma junção de esforços na coordenação de ações governamentais para a verificação das informações veiculadas nesses serviços, tais como ações do Congresso Nacional e de outros entes da Federação, com destaque para o combate às notícias falsas, por meio de projetos de lei com o intuito de legislar sobre o tema e criar mecanismos de punição para eventuais abusos, incluindo, nesse cenário, o contexto da pandemia de covid-19.

Portanto, o objetivo desta pesquisa é analisar as postagens em SRSO por parte de instituições governamentais relacionadas à pandemia de covid-19, especialmente o caráter de atuação informativa

1 A pesquisa apresentada tem aderência a iniciativas de análises qualitativas e quantitativas sobre informações da covid-19 e a seus desdobramentos, onde a junção de métodos das Ciências Sociais Aplicadas e das Ciências Exatas têm papel importante. e.g. Pesquisas de Mike Thelwall (2021). 
desses órgãos e a tempestividade ${ }^{2}$, com o propósito de identificar a relação entre as postagens e o suporte de documentos oficiais.

Como procedimentos metodológicos, foram delimitadas as seguintes ações: i) realizar coleta de dados das postagens dos órgãos, incluindo informações como: SRSO de onde a postagem foi coletada, a data de publicação, o hyperlink da mensagem e se a mensagem tem link para algum documento oficial que dê suporte à veracidade do conteúdo veiculado; ii) analisar as informações coletadas, incluindo o cálculo de representatividade de postagens com suporte de documentos oficiais, quais SRSO são mais utilizados e os períodos em que as postagens foram veiculadas no decorrer do ano durante o período de pandemia da covid-19; iii) verificar quais são os termos de classificação mais utilizados nos SRSO, durante a pandemia (somente as hashtags foram consideradas termos de classificação); e iv) realizar a análise dos documentos oficiais para compreender as características das fontes de informações oficiais que dão suporte à mensagem, quando o usuário é direcionado para os websites dessa instituição.

A amostra delimitou-se ao estudo das páginas oficiais dos Corpos de Bombeiros Militares dos estados do Pará, do Ceará, de São Paulo, de Santa Catarina e de Goiás nos SRSO Facebook, Instagram e Twitter. O critério para a escolha desses estados foi o fato de eles serem os estados com maior índice de infecção da covid-19 na região no momento da coleta de dados, realizada entre os dias 5 de março de 2020 e 29 de maio de 2020. Os SRSO escolhidos foram os que se configuravam como os mais utilizados no Brasil até a data de encerramento da coleta dos dados desta pesquisa (ALEXA, 2021).

Este artigo está dividido nas seguintes seções: a segunda seção apresenta uma breve trajetória da pandemia, o contexto da pandemia de covid-19 no Brasil e a repercussão do vírus nas regiões geográficas brasileiras; a terceira seção apresenta o contexto dos SRSO e os seus usos para compartilhamento de informações das instituições do Estado; a quarta seção apresenta informações sobre os Corpos de Bombeiros Militares analisados; a quinta seção apresenta os resultados e a discussão; e a sexta seção apresenta as considerações finais.

\section{O CONTEXTO DA PANDEMIA DE COVID-19}

A covid-19 é uma epidemia que ganhou notoriedade a partir de dezembro de 2019 e é responsável pela Síndrome Respiratória Aguda Grave coronavírus tipo 2, denominada SARS-CoV-2² (VILELAS, 2020). SARS refere-se à síndrome relacionada a uma das formas graves das doenças respiratórias e é caracterizado pela dificuldade de respiração dos pacientes infectados. CoV se refere à forma abreviada da palavra coronavírus, família do vírus a que pertence a doença; e o número 2 é utilizado devido à semelhança com outra espécie de coronavírus anterior, o SARS-CoV.

O início da pandemia ocorreu na República Popular da China, na província de Hubei, cuja capital é Wuhan - uma cidade industrial que está entre as mais populosas do país (SOUSA JÚNIOR et al., 2020). Posteriormente, a doença disseminou-se para outros países, causando uma pandemia mundial. A transmissão da covid-19 acontece por meio de contato com gotículas contaminadas por vias respiratórias e aerossóis, além de contato com fezes e superfícies com secreções (VILELAS, 2020).

A covid-19 apresenta sintomas semelhantes aos da gripe (febre, dores no corpo e na cabeça e tosse seca), além de quadros de pneumonia branda, leve, grave ou crítica (SOUSA JÚNIOR et al., 2020). Num mundo globalizado e com fluxo constante de pessoas entre os países, a transmissão do vírus não se limitou à República Popular da China, e todos os países foram afetados pela doença.

\footnotetext{
2 Termo utilizado no sentido de uma ação que ocorre no momento oportuno ou exato. No caso, compreender o tempo em que ocorrem as ações informativas de órgãos públicos, especialmente nos primeiros momentos de uma situação de crise. 
Um caso notório foi o da Itália, onde, a priori, não se realizou o contingenciamento de pessoas e o fechamento de parte do comércio, ou seja, a proposta de isolamento social e de quarentena ${ }^{4}$, indicada pela Organização Mundial da Saúde (OMS). O governo italiano optou por não seguir as indicações da OMS e iniciou a campanha 'Milano non si ferma' nos SRSO, 'Milão não para', em português. A consequência foi que o número de infectados aumentou consideravelmente na Itália. Com a propagação do vírus de forma acelerada no território italiano, a contaminação e os óbitos diários superaram os da República Popular da China e a média mundial do número de óbitos (SOUSA JÚNIOR et al., 2020).

Em termos globais, em 12 de fevereiro de 2021, os casos da pandemia da covid-19 eram: 107.423.526 infectados e 2.360.280 mortes (WHO, c2021; OPAS, c2021). Em cada região do globo os números eram: África - 2.703.899 infectados e 67.586 mortes; América - 47.814.602 infectados e 1.120.144 mortes; Europa - 36.294.484 casos e 805.071 mortes; Mediterrâneo Oriental - 5.951.021 casos e 138.834 mortes; Pacífico Ocidental - 1.516.916 casos e 26.804 mortes; e Sudeste Asiático - 13.141.859 casos e 201.828 mortes (WHO, c2021; OPAS, c2021).

\section{Contexto da covid-19 nas regiões do Brasil}

No Brasil, o primeiro caso confirmado de covid-19 foi identificado na região Sudeste, no dia 26 de fevereiro de 2020 - um paciente da terceira idade, do sexo masculino, residente no estado de São Paulo, que retornava de uma viagem à Itália (OLIVEIRA et al., 2020). A doença se espalhou rapidamente, e em pouco tempo constatou-se que o vírus já circulava em outras cidades. No dia 20 de março de 2020, foi declarada a crise sanitária nacional da covid-19.

Tabela 1 - Informações sobre a covid-19 no Brasil, no dia 22 de abril de 2021

\begin{tabular}{lccccc}
\multicolumn{1}{c}{ Região } & População & $\begin{array}{c}\text { Casos } \\
\text { acumulados }\end{array}$ & $\begin{array}{c}\text { Casos } \\
\text { acumulados } \\
\mathbf{1 0 0} \mathbf{~ m i}\end{array}$ & $\begin{array}{c}\text { Óbitos } \\
\text { acumulados }\end{array}$ & $\begin{array}{c}\text { Óbitos } \\
\text { acumulados } \\
\mathbf{1 0 0} \mathbf{~ m i}\end{array}$ \\
Sudeste & 88.371 .433 & 5.236 .315 & 5.925 & 173.558 & 196 \\
Sul & 29.975 .984 & 2.721 .414 & 9.079 & 57.627 & 192 \\
Nordeste & 57.071 .654 & 3.256 .316 & 5.706 & 79.550 & 139 \\
Centro-Oeste & 16.297 .074 & 1.492 .537 & 9.158 & 36.214 & 222 \\
Norte & 18.430 .980 & 1.461 .391 & 7.929 & 36.553 & 190 \\
Total & $\mathbf{2 1 0 . 1 4 7 . 1 2 5}$ & $\mathbf{1 4 . 1 6 7 . 9 7 3}$ & $\mathbf{3 7 . 7 9 7}$ & $\mathbf{3 8 3 . 5 0 2}$ & $\mathbf{9 3 9}$ \\
\hline
\end{tabular}

Fonte: adaptado pelos autores, baseado em Brasil (c2021).

Com uma população de 210.147.125, em 22 de abril de 2021, o Brasil tinha 14.167.973 de casos acumulados e 383.502 mortes. Essas informações são originárias do site oficial do governo do Brasil, denominado Covid-19 no Brasil (BRASIL, c2021), onde se encontram informações por região (ver Tabela 1).

4 Forma que ficou conhecida como o isolamento por 14 dias das pessoas com suspeita de infecção. Esse número de dias é referente ao período de incubação do vírus. 
Tabela 2 - Informações sobre a Covid-19 no Brasil, no dia 22 de abril de 2021 (com resultados apenas dos estados pesquisados com maior número de infectados)

\begin{tabular}{|c|c|c|c|c|c|c|c|}
\hline Região & População & $\begin{array}{l}\text { Casos } \\
\text { novos }\end{array}$ & $\begin{array}{c}\text { Casos } \\
\text { acumulados }\end{array}$ & $\begin{array}{c}\text { Casos } \\
\text { acumulados } \\
100 \mathrm{mi}\end{array}$ & $\begin{array}{l}\text { Óbitos } \\
\text { novos }\end{array}$ & $\begin{array}{c}\text { Óbitos } \\
\text { acumulados }\end{array}$ & $\begin{array}{c}\text { Óbitos } \\
\text { acumulados } \\
100 \mathrm{mi}\end{array}$ \\
\hline $\begin{array}{l}\text { Sudeste - } \\
\text { São Paulo }\end{array}$ & 45.919 .049 & 7.267 & 2.793 .750 & 6.084 & 183 & 90.810 & 198 \\
\hline $\begin{array}{l}\text { Sul - Rio } \\
\text { Grande } \\
\text { do Sul }\end{array}$ & 11.377 .239 & 869 & 935.839 & 8.226 & 62 & 23.752 & 209 \\
\hline $\begin{array}{l}\text { Nordeste - } \\
\text { Bahia }\end{array}$ & 14.873 .064 & 2.160 & 873.832 & 5.875 & 113 & 17.687 & 119 \\
\hline $\begin{array}{l}\text { Centro-Oeste } \\
\text { - Goiás }\end{array}$ & 7.018 .534 & 1.486 & 533.788 & 7.343 & 78 & 14.182 & 202 \\
\hline Norte - Pará & 8.602 .865 & 1.333 & 457.961 & 98 & 5.323 & 12.263 & 143 \\
\hline Total & 87.790 .571 & 13.115 & 5.595 .170 & 27.626 & 534 & 158.694 & 871 \\
\hline
\end{tabular}

Fonte: Brasil (c2021).

A Tabela 2 exibe o quantitativo da população de cada estado envolvido nesta pesquisa (em 22 de abril de 2021), incluindo a região em que está inserida: região Sudeste/São Paulo, região Norte/Pará, região Sul/ Rio Grande do Sul, região Nordeste/Bahia e região Centro-Oeste/Goiás. Na época desta pesquisa, esses eram os estados com o maior número de casos confirmados de covid-19.

\section{OS SERVIÇOS DE REDES SOCIAIS ON-LINE E A PANDEMIA DA COVID-19}

Castells (1999) afirma que, após a Segunda Guerra Mundial, foram desenvolvidas as principais tecnologias eletrônicas, desde a criação do primeiro computador e do transistor até os satélites artificiais e as redes de computadores, parte dos artefatos que compõem a Tecnologia da Informação (ALMEIDA, 2005). Nessa perspectiva, o termo rede está associado ao desenvolvimento de ferramentas tecnológicas da internet, ao trazer para a sociedade uma nova forma de relação, comunicação e organização das atividades humanas e ao considerar o estudo das redes sociais, mediadas por computadores, que utilizam vários recursos, tais como: grupo de notícias (mailing), e-mails, fóruns, listas de discussão e os serviços on-line voltados para as redes sociais (MACHADO, TIJIBOY, 2005).

As redes sociais já existiam antes da internet (RECUERO, 2014), e esse é um assunto que tem forte aderência na Sociologia e na Antropologia. Consequentemente, as redes sociais têm ligação com as metáforas de linguagem como tecidos e teias (sociais), devido ao entrelaçamento e à interconexão das relações humanas e coletivas. Vermelho et al. (2014) afirmam que as redes sociais crescem e evoluem com o uso das TIC, devido ao forte poder de propagação da informação.

As Redes Sociais On-line têm relação direta com um novo sistema de comunicação, mediado pelas TIC (CASTELLS, 1999) - sistema globalizado que proporciona novas experiências aos indivíduos, possibilitando, inclusive, a produção de materiais audiovisuais. Essas transformações estão interligadas às redes de computadores, que criam novos canais e uma nova forma de comunicação. Os primeiros SRSO surgiram em 2002 e 2003, respectivamente o Friendster e o MySpace. Para Rodrigues (2017), as RSO procuram estabelecer um ambiente informacional digital, por meio de serviços on-line, que aproxima os indivíduos ao transpor barreiras de conexões globais de espaço e de tempo.

Todavia, é importante enfatizar que os SRSO exercem um poder que suscita cuidados com relação ao que é publicado por cidadãos, governos e instituições, pois esses conteúdos são publicados e posteriormente 
utilizados para diversos fins, tais como: educação, pesquisa, estudos, posicionamentos políticos, comércios e serviços (CARVALHO, 2016).

Diversas empresas oferecem serviços com TIC para facilitar a interação dos seus participantes. Nesse sentido, os SRSO são desenvolvidos para:

[...] auxiliarem os processos de comunicação e de inter-relacionamento de pessoas e de instituições participantes, elaboradas e mantidas por uma ou mais instituições, onde é disponibilizado acesso por meio de ferramentas em websites ou por aplicativos e oferece acesso a parte dos dados armazenados de seus participantes para coleta por agentes externos. (RODRIGUES, SANT'ANA, 2018, p. 23)

Entre os SRSO, destacam-se, no contexto brasileiro, o Facebook, o Instagram e o Twitter, que se tornaram serviços de uso diário por parcela significativa da sociedade (LUZ NETO, 2017). Esses serviços são hoje os mais utilizados pelos usuários (ALEXA, c2021). Em 2019, 76\% dos brasileiros que acessaram a internet consultaram pelo menos um SRSO (NÚCLEO DE INFORMAÇÃO E COORDENAÇÃO DO PONTO $\mathrm{BR}, 2020)$.

Nesse contexto, é importante que órgãos vinculados ao combate à pandemia informem à população as melhores práticas de convivência social, para minimizar o problema trazido pela covid-19. Todavia, verifica-se que a veiculação de notícias falsas (RECUERO; SOARES, 2021) em SRSO é um problema não só relacionado à pandemia da covid-19, mas também a outras interações sociais, tais como interações políticas, questões de comportamento, alimentação e lazer.

$\mathrm{Na}$ área da saúde, as notícias falsas têm interferido no processo de vacinação, alimentação e tratamento de pacientes. Os usuários são levados a acreditar em informações veiculadas sobre procedimentos médicos que não têm validação científica ou consenso sobre eficácia comprovada por pesquisadores, o que, sem dúvida, compromete o trabalho desenvolvido pelos profissionais da área da saúde na prevenção de doenças (GOMES, 2020).

Contudo, a divulgação de notícias falsas não pode invalidar os benefícios que os SRSO representam - como possibilitar o contato entre pessoas distantes. É importante que se busquem mecanismos que legitimem as informações e que esses serviços passem confiança, por exemplo, quando da necessidade de se pesquisar determinada informação, principalmente em um momento de pandemia, em que há uma carência de fontes confiáveis (YANG et al., 2021).

Desse modo, criar mecanismos de combate às notícias falsas veiculadas nos SRSO perpassa pela legislação, principalmente as que são relacionadas ao acesso e ao compartilhamento de informações. De acordo com artigo quinto da Constituição Federal (BRASIL, 1988), inciso XXXIII: "[...] todos têm direito a receber dos órgãos públicos informações de seu interesse particular, ou de interesse coletivo em geral [...]", complementado pela lei $\mathrm{n}^{\mathrm{o}} 12.527 / 2011$, art. $4^{\mathrm{o}}$, inciso I, que considera a informação como "[...] dados, processados ou não, que podem ser utilizados para a produção e transmissão de conhecimentos, contidos em qualquer meio, suporte ou formato" (BRASIL, 2011, p. 1).

\section{O CORPO DE BOMBEIROS MILITAR}

O Corpo de Bombeiros Militar do Estado do Rio de Janeiro (CBMERJ) é o mais antigo do Brasil, estabelecido por d. Pedro II, no decreto $\mathrm{n}^{0}$ 1.775, de 02 de julho de 1856 , que regulamentara o serviço de Extinção de Incêndios. Em 19 de julho de 1880, a corporação conquistou o status militar pelo decreto imperial $n^{0} 7.766$, e a sua capacitação técnica tem origem no Corpo de Engenheiros do Exército Brasileiro (BASTOS, 2016). 
Reciis - Revista Eletrônica de Comunicação, Informação \& Inovação em Saúde, Rio de Janeiro, v. 16, n.1, p. 139-158, jan.-mar. 2022 [www.reciis.icict.fiocruz.br] e-ISSN 1981-6278

Atualmente, os Corpos de Bombeiros Militares são regidos pela Constituição Federal, no capítulo III, distinguidos como componentes da Segurança Pública (ver artigo 144, parágrafo V, BRASIL, 1988). Segundo o parágrafo VI do mesmo artigo, a Polícia Militar e os Corpos de Bombeiros são forças auxiliares e reservas do Exército brasileiro. Segundo Francischelli (2019), esta relação com o Exército brasileiro contribui com a Polícia Militar e com os Bombeiros Militares nos serviços ostensivos e na preservação da Ordem Pública, estando ambos subordinados aos governadores dos estados, do Distrito Federal e dos territórios (BRASIL, 1988).

O Corpo de Bombeiros do Estado de Goiás (CBMGO) surgiu devido aos incêndios ocorridos na capital do estado, especialmente o incêndio que aconteceu no Palácio do Governo no ano de 1957. No ano de 1958, foi editada a lei $n^{0}$ 2.400, que criava a Companhia de Bombeiros da capital, sediada nas dependências da Polícia Militar. Posteriormente, a Companhia de Bombeiros se tornou independente e autônoma, com a criação da Constituição Estadual, de 05 de outubro de 1989, instituindo o Corpo de Bombeiros Militar do Estado de Goiás como componente da Segurança Pública. Desde o ano 2000, o comando-geral fica localizado na sede da Secretaria de Segurança Pública, situada na avenida Anhanguera, $\mathrm{n}^{0} 7.364$, no setor Aeroviário (CORPO DE BOMBEIROS MILITAR DO ESTADO DE GOIÁS, 2021).

O CBMGO veicula suas informações ao público por meio do site oficial (https://www.bombeiros.go.gov. br) e dos SRSO Facebook (https://www.facebook.com/cbmgo), Instagram (https://www.instagram.com/cbmgo/) e Twitter (https://twitter.com/cbmgo) (CORPO DE BOMBEIROS MILITAR DO ESTADO DE GOIÁS, 2021).

O Corpo de Bombeiros Militar do Estado do Ceará (CBMCE) foi denominado inicialmente Pelotão de Bombeiros. Foi criado como instituição, no dia 08 de agosto de 1925, pela lei $n^{0} 2.253$, promulgada pelo desembargador José Moreira da Rocha, governador do estado. Inicialmente, o pelotão combatia os incêndios apenas na cidade de Fortaleza. No ano de 1934, passou a ser chamado em definitivo de Corpo de Bombeiros do Estado do Ceará, parte da Segurança Pública do estado. Sua sede, denominada Comando de Bombeiros da Capital (CBC), fica localizada na rua Oto Alencar, $\mathrm{n}^{0} 2.015$, no bairro de Jacarecanga, na cidade de Fortaleza (CORPO DE BOMBEIROS MILITAR DO CEARÁ, 2009).

As informações do CBMCE podem ser encontradas em seu site oficial (https://www.bombeiros.ce.gov.br/ institucional) e nos SRSO Facebook (https://www.facebook.com/CBMCE), Instagram (https://www.instagram.com/ cbm.ce) e Twitter (https://twitter.com/bombeirosceara) (CORPO DE BOMBEIROS MILITAR DO CEARÁ, 2009).

O Corpo de Bombeiros Militar do Pará (CBMPA) foi criado no dia 24 de novembro de 1882, pela publicação da portaria provincial. Inicialmente era ligado à Companhia da Polícia Militar. Posteriormente, emancipou-se e obteve autonomia com um novo regime jurídico, com a promulgação da Constituição Estadual, de 05 de outubro de 1989, passando a ser subordinado ao governo do estado do Pará e a se chamar Corpo de Bombeiros Militar do Pará. Na nova Constituição Estadual, unificou-se o comando do CBMPA com a Coordenadoria Estadual de Defesa Civil. Atualmente, a sede do quartel de comando-geral fica localizada na cidade de Belém, na avenida Júlio César, nº 3.00o, no bairro de Val-de-Cães (CORPO DE BOMBEIROS MILITAR DO PARÁ E COORDENADORIA ESTADUAL DE DEFESA CIVIL, 2021)

O CBMPA divulga suas informações em seu site oficial (https://www.bombeiros.pa.gov.br) e nos SRSO Facebook (https://www.facebook.com/cbmPARA), Instagram (https://www.instagram.com/cbmpa) e Twitter (https://twitter.com/CBMPA) (CORPO DE BOMBEIROS MILITAR DO PARÁ E COORDENADORIA ESTADUAL DE DEFESA CIVIL, c2021).

No estado de São Paulo, de início os serviços de bombeiros eram limitados, pois ainda eram executados por policiais militares. Somente em 10 de março de 1880 foi estabelecida a autorização ao governo provincial para criar uma seção de bombeiros, que ficaria anexa à Companhia de Urbanos da Capital, pela Assembleia Legislativa provençal, via lei $n^{0}$ 6. Com isso, os bombeiros poderiam aumentar seu efetivo e dedicar-se exclusivamente ao combate dos incêndios, além de adquirir maquinários próprios para os serviços. Pela 
primeira vez, o estado de São Paulo teria um efetivo que trabalharia especificamente nos serviços de bombeiros. O endereço atual do comando do Corpo de Bombeiros de São Paulo fica situado na Praça Clóvis Beviláqua, $\mathrm{n}^{0}$ 421, Centro (CORPO DE BOMBEIROS SÃO PAULO, c2021).

As informações dos serviços do Corpo de Bombeiros da Polícia Militar do Estado de São Paulo (CBPMESP) são divulgadas no site oficial (http://www.corpodebombeiros.sp.gov.br) e nos SRSO Facebook (https://www. facebook.com/corpodebombeirosdapmesp), Instagram (https://www.instagram.com/corpodebombeirosdapmesp) e Twitter (https://twitter.com/BombeirosPMESP) (CORPO DE BOMBEIROS SÃO PAULO, 2021).

A criação do Corpo de Bombeiros Militar do Estado de Santa Catarina (CBMSC) se deu por vários motivos: uma repercussão na imprensa florianopolitana no ano de 1919, o clamor do povo somado ao pedido de empresários que viam seus comércios em perigo por conta da ausência desse serviço essencial. Em 1919, ocorreu um incêndio na esquina da rua Trajano com a rua Conselheiro Mafra, danificando prédios e comércios da capital. Um fator-chave foi que, no momento do incêndio, estava sendo celebrado um culto religioso da programação da Semana Santa, o que causou comoção e insatisfação na população pelo fato do município não possuir meios adequados de combate a incêndios. Por conta disso, o então governador do estado de Santa Catarina, Hercílio Luz, assinou a lei $\mathrm{n}^{0}$ 1.288, em 16 de setembro de 1919, que criava a Seção de Bombeiros da Força Pública. Atualmente, a sede do Corpo de Bombeiros de Santa Catarina fica no quartel do comando-geral, rua Almirante Lamego, $\mathrm{n}^{\circ} 381$, Centro (CORPO DE BOMBEIROS MILITAR DE SANTA CATARINA, 2021).

As informações dos serviços do CBMSC são divulgadas no site oficial (https://www.cbm.sc.gov.br) e também pelos SRSO Facebook (https://www.facebook.com/cbmscoficial), Instagram (https://www.instagram. com/cbmscoficial) e Twitter (https://twitter.com/cbmscoficial) (CORPO DE BOMBEIROS MILITAR DE SANTA CATARINA, 2021).

\section{RESULTADOS E DISCUSSÃO}

Os resultados estão divididos conforme os critérios estabelecidos nos procedimentos metodológicos. Na primeira parte são apresentados os dados coletados. A segunda parte apresenta: a) o cálculo de representatividade de postagens com suporte de documentos oficiais; b) os SRSO mais utilizados; e c) os períodos em que as postagens foram veiculadas durante o período de pandemia da covid-19. A terceira parte explicita quais são os termos de classificação de conteúdo mais utilizados nos SRSO, durante a pandemia, no qual apenas as hashtags foram consideradas termos relevantes. A quarta parte detalha a análise dos documentos oficiais para compreender as características das fontes de informações oficiais que dão suporte às postagens veiculadas.

\section{Dados coletados}

Foram analisadas as postagens dos Corpos de Bombeiros Militares publicadas entre os dias 5 de março de 2020 e 29 de maio de 2020, nos SRSO (Facebook, Twitter e Instagram). A escolha do período é justificada pelo escopo da pesquisa e o enfoque foi dado às primeiras iniciativas informativas dos órgãos no primeiro estágio da pandemia. Foram coletadas um total de 396 postagens, com as seguintes informações: a sigla do Corpo de Bombeiros Militar; o nome do Serviço de Rede Social On-line em que foi feita a postagem; a data da publicação; a mensagem textual da postagem; o hyperlink da postagem veiculada no SRSO; e o hyperlink do documento oficial, caso a postagem direcionasse para um documento oficial do Corpo de Bombeiros Militar. Optou-se por não descartar nenhuma postagem. 
Tabela 3 - Quantidade de postagens coletadas, segmentada por Corpos de Bombeiros Militares

\begin{tabular}{lcc}
\multicolumn{1}{c}{ Sigla } & Total & Total (\%) \\
\hline CBMGO & 135 & $34,09 \%$ \\
CBMSC & 114 & $28,79 \%$ \\
CBMPA & 83 & $20,96 \%$ \\
CBPMESP & 35 & $8,84 \%$ \\
CBMCE & 29 & $7,32 \%$ \\
Total & $\mathbf{3 9 6}$ & $\mathbf{1 0 0 , 0 0 \%}$ \\
\hline
\end{tabular}

Fonte: elaboração dos autores.

A Tabela 3 apresenta a quantidade de postagens coletadas, segmentada por Corpos de Bombeiros Militares, ordenada pelo Corpo de Bombeiros Militar que mais apresentou postagens sobre a covid-19. O CBMGO teve o maior número de postagens, um total de 135, representando 34,09\% do total de postagens coletadas. Em seguida, o CBMSC, teve 114 postagens (28,79\% do total de postagens). O terceiro colocado, CBMPA, publicou 83 postagens, representando 20,96\% do total. O quarto colocado foi o CBPMESP, com 35 postagens (8,84\% do total); e, em último, o CBMCE, com 29 (7,32\% do total de postagens).

Nota-se que não há relação direta entre a quantidade de postagens e os totais de casos e óbitos acumulados para os estados analisados. Destaca-se também que a população de cada estado não interfere na quantidade de ações informativas dos Corpos de Bombeiros Militares nos SRSO analisados.

\section{Análise dos dados das postagens}

A Tabela 4 apresenta o total de postagens que vincula mensagem a um documento, segmentado por Corpos de Bombeiros Militares e por SRSO. A partir dos resultados obtidos, é possível indicar que uma baixa quantidade de postagens relaciona o conteúdo com algum tipo de documento oficial (apenas 20 postagens).

Tabela 4-Total de postagens vinculadas a um documento, segmentado por Corpos de Bombeiros Militares e por Serviços de Redes Sociais On-line

\begin{tabular}{lcccccccc}
\multicolumn{1}{c}{ Sigla } & Facebook & Instagram & Twitter & Total & $\begin{array}{c}\text { Facebook } \\
\mathbf{( \% )}\end{array}$ & $\begin{array}{c}\text { Instagram } \\
(\mathbf{\%})\end{array}$ & $\begin{array}{c}\text { Twitter } \\
\mathbf{( \% )}\end{array}$ & $\begin{array}{c}\text { Total } \\
(\mathbf{\%})\end{array}$ \\
CBMPA & 10 & 0 & 6 & 16 & $83,33 \%$ & $0,00 \%$ & $85,71 \%$ & $80,00 \%$ \\
CBPMESP & 0 & 0 & 0 & 0 & $0,00 \%$ & $0,00 \%$ & $0,00 \%$ & $0,00 \%$ \\
CBMGO & 0 & $1^{5}$ & 0 & $1^{5}$ & $0,00 \%$ & $100,00 \% 5$ & $0,00 \%$ & $5,00 \%{ }^{5}$ \\
CBMCE & 0 & 0 & 0 & 0 & $0,00 \%$ & $0,00 \%$ & $0,00 \%$ & $0,00 \%$ \\
CBMSC & $2^{6}$ & 0 & $1^{6}$ & $3^{6}$ & $16,67 \%$ & $0,00 \%$ & $14,29 \%$ & $15,00 \%$ \\
Total & $\mathbf{1 2}$ & $\mathbf{1}$ & $\mathbf{7}$ & $\mathbf{2 0}$ & $\mathbf{6 0 , 0 0 \%}$ & $\mathbf{5 , 0 0 \%}$ & $\mathbf{3 5 , 0 0 \%}$ & $\mathbf{1 0 0 , 0 0 \%}$ \\
\hline
\end{tabular}

Fonte: elaboração dos autores.

Descartaram-se quatro postagens, por se tratar de vínculos para websites que direcionam o cidadão para outras plataformas, conforme as notas da Tabela 4. Verificou-se que apenas o CBMPA vinculou suas postagens a documentos oficiais; as particularidades dessas postagens são explicitadas na seção 5.4 desta pesquisa.

Portanto, o percentual de representatividade desse tipo de postagem é muito baixo, quando comparado com o total de postagens analisadas nesta pesquisa. Postagens vinculadas a documentos representam 5,05\% do total de postagens, sendo que 4,04\% do total direciona para websites de órgãos (ver Tabela 5). 
Tabela 5 - Comparação entre o total de postagens e as postagens que vinculam a mensagem a um documento, segmentado por Corpos de Bombeiros Militares e por Serviços de Redes Sociais On-line

\begin{tabular}{|c|c|c|c|c|}
\hline \multirow[t]{2}{*}{ Sigla } & \multicolumn{4}{|c|}{ Percentual de postagens com hyperlink, comparado com o total de postagens } \\
\hline & Facebook & Instagram & Twitter & Total \\
\hline CBMPA & $2,52 \%$ & $0,00 \%$ & $1,52 \%$ & $4,04 \%$ \\
\hline CBPMESP & $0,00 \%$ & $0,00 \%$ & $0,00 \%$ & $0,00 \%$ \\
\hline CBMGO & $0,00 \%$ & $0,25 \%{ }^{5}$ & $0,00 \%$ & $0,25 \%{ }^{5}$ \\
\hline CBMCE & $0,00 \%$ & $0,00 \%$ & $0,00 \%$ & $0,00 \%$ \\
\hline CBMSC & $0,51 \%$ & $0,00 \%$ & $0,25 \%$ & $0,76 \%$ \\
\hline Total & $3,03 \%$ & $0,25 \%$ & $1,77 \%$ & $5,05 \%$ \\
\hline
\end{tabular}

Fonte: elaboração dos autores.

Com relação aos SRSO utilizados para as postagens, os Corpos de Bombeiros Militares utilizaram o Instagram como SRSO primário para comunicação com os cidadãos (ver Tabela 6), locus de publicação de 53,79\% das postagens analisadas. Também é relevante destacar que o Instagram foi o SRSO adotado por boa parte das interações dos Corpos de Bombeiros Militares de Goiás e de Ceará, respectivamente representando $75,56 \%$ e $68,97 \%$ das postagens (valores destacados com o grifo verde na Tabela 6).

Tabela 6 - Serviços de Redes Sociais On-line utilizados para as postagens, segmentados por Corpos de Bombeiros Militares e por Serviços de Redes Sociais On-line

\begin{tabular}{|c|c|c|c|c|c|c|c|c|c|c|c|c|}
\hline $\begin{array}{l}\text { Serviço de } \\
\text { Rede Social } \\
\text { On-line }\end{array}$ & CBMGO & CBMSC & CBMPA & CBPMESP & CBMCE & Total & $\begin{array}{c}\text { CBMGO } \\
(\%)\end{array}$ & $\begin{array}{c}\text { CBMSC } \\
(\%)\end{array}$ & $\begin{array}{c}\text { CBMPA } \\
(\%)\end{array}$ & $\begin{array}{c}\text { CBPMESP } \\
(\%)\end{array}$ & $\begin{array}{c}\text { CBMCE } \\
(\%)\end{array}$ & $\begin{array}{l}\text { Total } \\
(\%)\end{array}$ \\
\hline Instagram & 102 & 41 & 33 & 17 & 20 & 213 & $75,56 \%$ & $35,96 \%$ & $39,76 \%$ & $48,57 \%$ & $68,97 \%$ & $53,79 \%$ \\
\hline Facebook & 24 & 41 & 33 & 18 & 9 & 125 & $17,78 \%$ & $35,96 \%$ & $39,76 \%$ & $51,43 \%$ & $31,03 \%$ & $31,57 \%$ \\
\hline Twitter & 9 & 32 & 17 & 0 & 0 & 58 & $6,67 \%$ & $28,07 \%$ & $20,48 \%$ & $0,00 \%$ & $0,00 \%$ & $14,64 \%$ \\
\hline Total & 135 & 114 & 83 & 35 & 29 & 396 & $34,09 \%$ & $28,79 \%$ & $20,96 \%$ & $8,84 \%$ & $7,32 \%$ & $100,00 \%$ \\
\hline
\end{tabular}

Fonte: elaboração dos autores.

Outros fatores relevantes a serem ponderados são a baixa incidência de postagens no Twitter (14,65\%) e a ausência de postagens neste serviço pelos Corpos de Bombeiros Militares de São Paulo e do Ceará (valores destacados com o grifo vermelho na Tabela 6). O Corpo de Bombeiros Militar de Santa Catarina apresentou equilíbrio de publicações nos três SRSO analisados: 35,96\% das postagens no Instagram e no Facebook (respectivamente) e 28,07\% no Twitter. O Corpo de Bombeiros Militar do Pará tem uma taxa aproximada de uma postagem no Twitter para duas postagens no Instagram e no Facebook.

Considerando a questão de tempestividade nas postagens sobre a covid-19 pelos Corpos de Bombeiros Militares, a Figura 1 apresenta o total de postagens diárias segmentado por SRSO. No intervalo de coleta de dados desta pesquisa, foram identificadas postagens de, ao menos, uma publicação por parte dos Corpos de Bombeiros Militares nos SRSO em 69 dias, sendo que a primeira postagem foi realizada no dia 05 de março de 2020. 


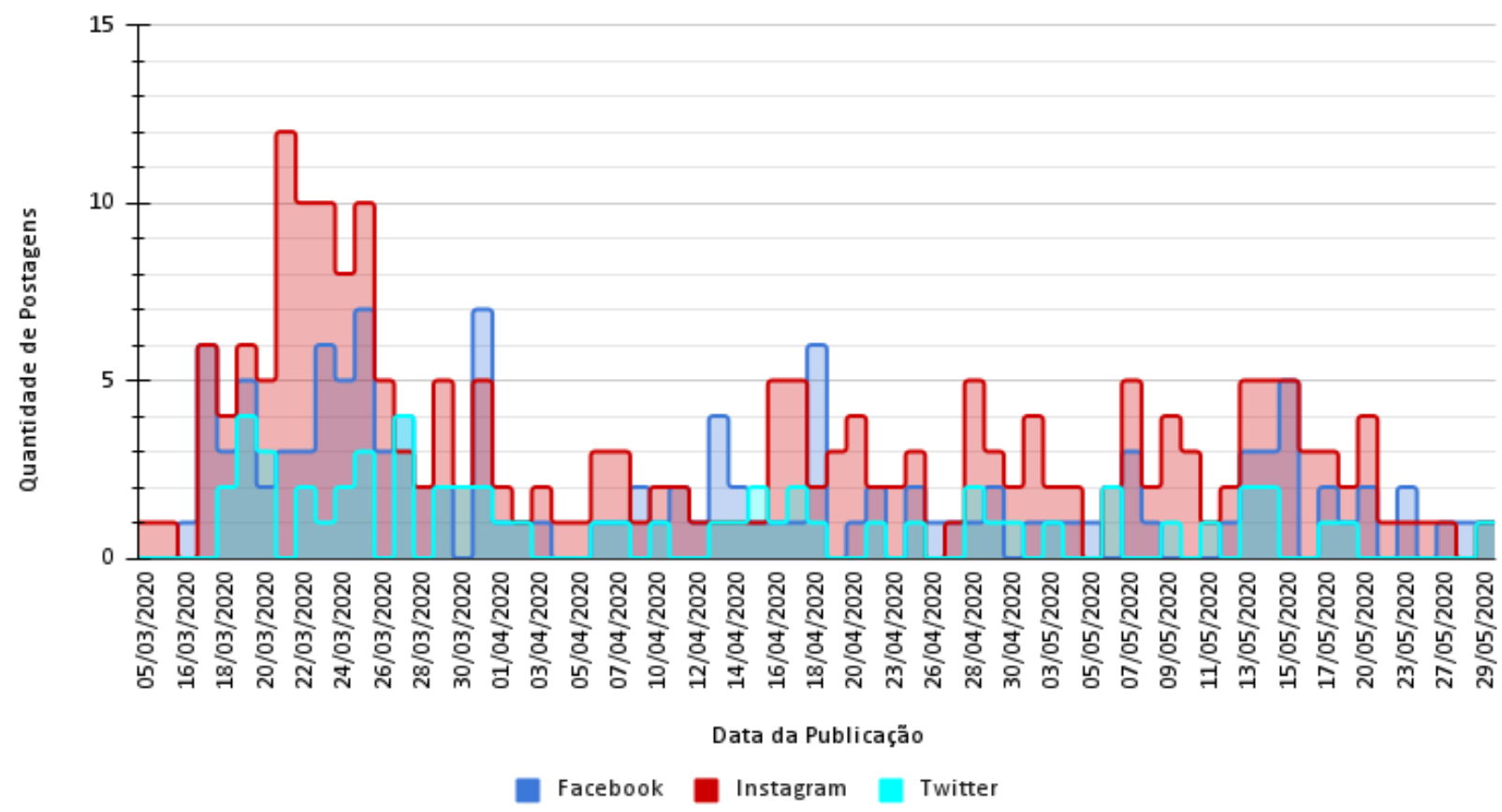

Figura 1 - Total de postagens diárias em Serviços de Redes Sociais On-line, segmentado por serviços de Redes Sociais On-line

Fonte: elaboração dos autores.

Verificou-se uma tempestividade por parte dos CBMs no início da pandemia, ao veicular postagens sobre a covid-19, sobretudo no Instagram, que apresentou um pico de postagens em 21 de março de 2020. Também é perceptível uma elevação da quantidade de publicações entre os dias 17 de março de 2020 e 21 de março de 2020. Após este período, ocorreu uma diminuição na taxa de publicação, estabilizando-se entre zero e seis postagens diárias.

Com relação às publicações realizadas por Corpos de Bombeiros Militares, a Figura 2 apresenta o total de postagens diárias em SRSO, segmentado por Corpos de Bombeiros Militares. Verifica-se que o pico de postagens tem relação direta com a atuação dos Corpos de Bombeiros Militares dos estados de Santa Catarina, Goiás e Pará; além do Corpo de Bombeiros Militar do estado de São Paulo, este com menor intensidade. Com relação à atuação dos Corpos de Bombeiros Militares em outros períodos, há uma boa distribuição, não se permitindo verificar algum tipo de preponderância de postagens por parte de algum deles. 


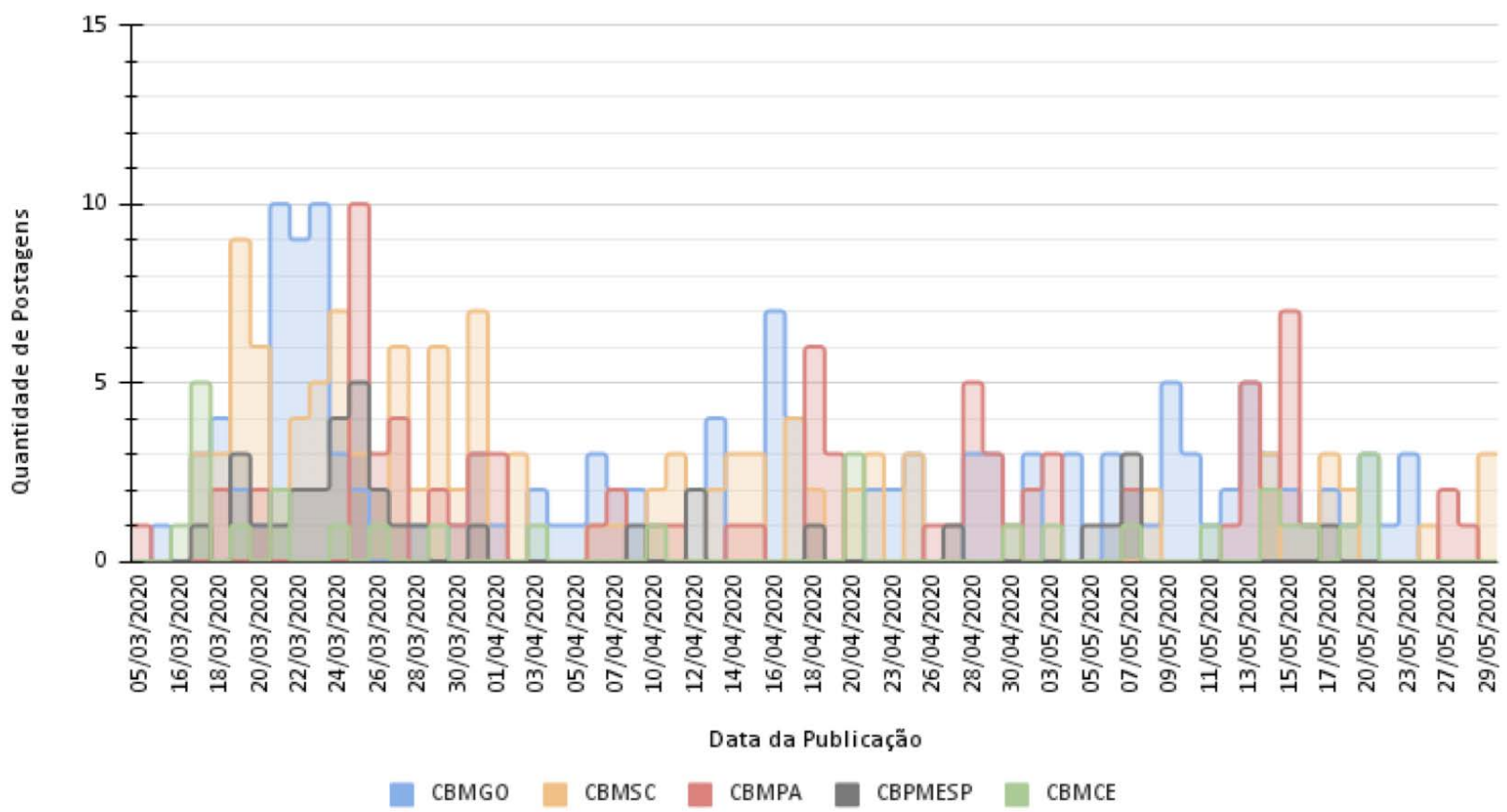

Figura 2 - Total de postagens diárias em Serviços de Redes Sociais On-line, segmentado por Corpos de Bombeiros Militares

Fonte: elaboração dos autores.

É importante enfatizar que se optou por não se analisarem as postagens com vínculos em documentação oficial, devido à baixa incidência.

\section{Termos de classificação utilizados nas postagens}

Para realizar a análise dos termos de classificação das postagens, optou-se por não realizar o tratamento de erros ortográficos (e.g. \#goais (sic) para \#goiás); as equivalências de gênero ou grau; o tratamento de variantes do termo; o uso de caracteres especiais que diferem dois termos aparentemente iguais por se tratar de caracteres com códigos diferentes para o padrão UTF-8 (adotado na coleta de dados). Também se optou por analisar somente os termos no formato de hashtags (palavras com o uso do símbolo \# no prefixo), já que se trata da principal estratégia dos SRSO de categorização por folksonomia. ${ }^{5}$

A pesquisa identificou 170 termos, sendo que 26 termos têm ocorrência igual ou maior que 10 postagens. Nesse sentido, utilizou-se a expressão $\mathrm{n}>=10$ como ocorrência mínima para análise, descartando-se os termos com menor incidência e, consequentemente, menor representatividade.

A Tabela 7 apresenta os termos mais utilizados para classificação das postagens em cada SRSO. É possível determinar que o uso de termos relacionados com a Covid-19 e o isolamento social destaca-se dos demais. Em um segundo plano, aparecem termos relacionados ao contexto dos Corpos de Bombeiros Militares, que classificam o conteúdo a partir do órgão que está publicando a mensagem (e.g. \#bombeiro). Em terceiro plano aparecem termos utilizados para georreferenciar a classificação do conteúdo informacional (e.g. \#brasil, \#ceará e \#goiás). 
Tabela 7-Termos mais utilizados para a classificação das postagens em Serviços de Redes Sociais Online, segmentados por Serviços de Redes Sociais On-line

\begin{tabular}{|c|c|c|c|c|c|c|c|c|c|}
\hline \# & Termos & Facebook & Instagram & Twitter & Total & $\begin{array}{c}\text { Facebook } \\
(\%)\end{array}$ & $\begin{array}{c}\text { Instagram } \\
(\%)\end{array}$ & $\begin{array}{c}\text { Twitter } \\
(\%)\end{array}$ & $\begin{array}{l}\text { Total } \\
(\%)\end{array}$ \\
\hline 1 & \#covid & 37 & 78 & 15 & 130 & $13,60 \%$ & $9,23 \%$ & $10,79 \%$ & $10,35 \%$ \\
\hline 2 & \#covid19 & 36 & 75 & 14 & 125 & $13,24 \%$ & $8,88 \%$ & $10,07 \%$ & $9,95 \%$ \\
\hline 3 & \#fique & 27 & 68 & 20 & 115 & $9,93 \%$ & $8,05 \%$ & $14,39 \%$ & $9,16 \%$ \\
\hline 4 & \#fiqueemcasa & 27 & 64 & 20 & 111 & $9,93 \%$ & $7,57 \%$ & $14,39 \%$ & $8,84 \%$ \\
\hline 5 & \#cbmsc & 34 & 40 & 25 & 99 & $12,50 \%$ & $4,73 \%$ & $17,99 \%$ & $7,88 \%$ \\
\hline 6 & \#coronavírus & 33 & 35 & 25 & 93 & $12,13 \%$ & $4,14 \%$ & $17,99 \%$ & $7,40 \%$ \\
\hline 7 & \#bombeiro & 7 & 82 & 2 & 91 & $2,57 \%$ & $9,70 \%$ & $1,44 \%$ & $7,25 \%$ \\
\hline 8 & \#bombeiros & 7 & 81 & 2 & 90 & $2,57 \%$ & $9,59 \%$ & $1,44 \%$ & $7,17 \%$ \\
\hline 9 & \#cbmgo & 3 & 70 & 1 & 74 & $1,10 \%$ & $8,28 \%$ & $0,72 \%$ & $5,89 \%$ \\
\hline 10 & \#coronavirus & 5 & 40 & 1 & 46 & $1,84 \%$ & $4,73 \%$ & $0,72 \%$ & $3,66 \%$ \\
\hline 11 & \#prevenção & 15 & 25 & 6 & 46 & $5,51 \%$ & $2,96 \%$ & $4,32 \%$ & $3,66 \%$ \\
\hline 12 & \#covid19 & 3 & 26 & 1 & 30 & $1,10 \%$ & $3,08 \%$ & $0,72 \%$ & $2,39 \%$ \\
\hline 13 & \#bombeirosgoias & 0 & 27 & 0 & 27 & $0,00 \%$ & $3,20 \%$ & $0,00 \%$ & $2,15 \%$ \\
\hline 14 & \#quarentena & 2 & 23 & 0 & 25 & $0,74 \%$ & $2,72 \%$ & $0,00 \%$ & $1,99 \%$ \\
\hline 15 & \#193 & 2 & 11 & 1 & 14 & $0,74 \%$ & $1,30 \%$ & $0,72 \%$ & $1,11 \%$ \\
\hline 16 & \#brasil & 3 & 10 & 0 & 13 & $1,10 \%$ & $1,18 \%$ & $0,00 \%$ & $1,04 \%$ \\
\hline 17 & \#cbmce & 3 & 10 & 0 & 13 & $1,10 \%$ & $1,18 \%$ & $0,00 \%$ & $1,04 \%$ \\
\hline 18 & \#ceara & 3 & 10 & 0 & 13 & $1,10 \%$ & $1,18 \%$ & $0,00 \%$ & $1,04 \%$ \\
\hline 19 & \#fortaleza & 3 & 10 & 0 & 13 & $1,10 \%$ & $1,18 \%$ & $0,00 \%$ & $1,04 \%$ \\
\hline 20 & \#goiás & 3 & 9 & 1 & 13 & $1,10 \%$ & $1,07 \%$ & $0,72 \%$ & $1,04 \%$ \\
\hline 21 & \#governodoceara & 3 & 10 & 0 & 13 & $1,10 \%$ & $1,18 \%$ & $0,00 \%$ & $1,04 \%$ \\
\hline 22 & \#militar & 3 & 10 & 0 & 13 & $1,10 \%$ & $1,18 \%$ & $0,00 \%$ & $1,04 \%$ \\
\hline 23 & \#sspds & 3 & 10 & 0 & 13 & $1,10 \%$ & $1,18 \%$ & $0,00 \%$ & $1,04 \%$ \\
\hline 24 & \#stayhome & 5 & 5 & 3 & 13 & $1,84 \%$ & $0,59 \%$ & $2,16 \%$ & $1,04 \%$ \\
\hline 25 & \#saúde & 2 & 8 & 2 & 12 & $0,74 \%$ & $0,95 \%$ & $1,44 \%$ & $0,96 \%$ \\
\hline \multirow[t]{2}{*}{26} & \#coronavirusbrasil & 3 & 8 & 0 & 11 & $1,10 \%$ & $0,95 \%$ & $0,00 \%$ & $0,88 \%$ \\
\hline & Total & 272 & 845 & 139 & 1.256 & $21,66 \%$ & $67,28 \%$ & $11,07 \%$ & $100,00 \%$ \\
\hline
\end{tabular}

Fonte: elaboração dos autores.

A análise dos termos, a partir das postagens realizadas em cada SRSO, também permite a percepção de uma equidade relativa na utilização dos termos, destoando apenas os termos \#bombeiro, \#bombeiros e \#cbmgo no SRSO Instagram, e \#prevenção no caso do SRSO Facebook. Outro fator de destaque é o uso de termos de classificação no SRSO Instagram - 67,28\% do total de ocorrências (destacado com o grifo verde na Tabela 7). 
Tabela 8 - Termos mais utilizados para a classificação das postagens em Serviços de Redes Sociais Online, segmentados por Corpos de Bombeiros Militares

\begin{tabular}{|c|c|c|c|c|c|c|c|c|c|c|c|c|c|c|c|c|c|c|c|c|}
\hline \multirow{2}{*}{ \# 1} & \multirow{2}{*}{ Termos } & \multicolumn{4}{|c|}{ CBMGO } & \multicolumn{4}{|c|}{ CBMSC } & \multicolumn{3}{|c|}{ CBMPA } & \multicolumn{3}{|c|}{ CBPMESP } & \multicolumn{4}{|c|}{ CBMCE } & \\
\hline & & $\mathbf{F}$ & I & T 1 & Total & $\mathbf{F}$ & $\mathbf{I}$ & $\mathbf{T}$ & Total & $\mathbf{F}$ & I $\mathbf{T}$ & Total & $\mathbf{F}$ & I 1 & T Total & $F$ & I & & otal & \\
\hline 1 & \#covid & 4 & 39 & 2 & 45 & 30 & 31 & 13 & 74 & 0 & 00 & 0 & 0 & 00 & 0 & 3 & 8 & 0 & 11 & 130 \\
\hline 2 & \#covid19 & 4 & 38 & 1 & 43 & 30 & 31 & 13 & 74 & 0 & 00 & 0 & 0 & 00 & 0 & 2 & 6 & 0 & 8 & 125 \\
\hline 3 & \#fique & 4 & 39 & 5 & 48 & 21 & 23 & 14 & 58 & 0 & 01 & 1 & 0 & 0 & 0 & 2 & 6 & 0 & 8 & 115 \\
\hline 4 & \#fiqueemcasa & 4 & 35 & 5 & 44 & 21 & 23 & 14 & 58 & 0 & 01 & 1 & 0 & 00 & 0 & 2 & 6 & 0 & 8 & 111 \\
\hline 5 & \#cbmsc & 0 & 0 & 0 & 0 & 34 & 40 & 25 & 99 & 0 & 00 & 0 & 0 & 0 & 0 & 0 & 0 & 0 & 0 & 99 \\
\hline 6 & \#coronavírus & 0 & 0 & 0 & 0 & 33 & 35 & 25 & 93 & 0 & 00 & 0 & 0 & 0 & 0 & 0 & 0 & 0 & 0 & 93 \\
\hline 7 & \#bombeiro & 4 & 64 & 2 & 70 & 0 & 1 & 0 & 1 & 0 & 00 & 0 & 0 & 60 & 6 & 3 & 11 & 0 & 14 & 91 \\
\hline 8 & \#bombeiros & 4 & 63 & 2 & 69 & 0 & 1 & 0 & 1 & 0 & 00 & 0 & 0 & 60 & 6 & 3 & 11 & 0 & 14 & 90 \\
\hline 9 & \#cbmgo & 3 & 70 & 1 & 74 & 0 & 0 & 0 & 0 & 0 & 00 & 0 & 0 & 0 & 0 & 0 & 0 & 0 & 0 & 74 \\
\hline 10 & \#coronavirus & 2 & 30 & 1 & 33 & 0 & 0 & 0 & 0 & 0 & 00 & 0 & 0 & 10 & 1 & 3 & 9 & 0 & 12 & 46 \\
\hline 11 & \#prevenção & 0 & 7 & 0 & 7 & 15 & 18 & 6 & 39 & 0 & 00 & 0 & 0 & 0 & 0 & 0 & 0 & 0 & 0 & 46 \\
\hline 12 & \#covid19 & 2 & 24 & 0 & 26 & 1 & 1 & 1 & 3 & 0 & 00 & 0 & 0 & 0 & 0 & 0 & 1 & 0 & 1 & 30 \\
\hline 13 & \#bombeirosgoias & 0 & 27 & 0 & 27 & 0 & 0 & 0 & 0 & 0 & 00 & 0 & 0 & 0 & 0 & 0 & 0 & 0 & 0 & 27 \\
\hline 14 & \#quarentena & 2 & 23 & 0 & 25 & 0 & 0 & 0 & 0 & 0 & 00 & 0 & 0 & 00 & 00 & 0 & 0 & 0 & 0 & 25 \\
\hline 15 & \#193 & 2 & 7 & 1 & 10 & 0 & 0 & 0 & 0 & 0 & 00 & 0 & 0 & $4 c$ & 04 & 0 & 0 & 0 & 0 & 14 \\
\hline 16 & \#brasil & 0 & 0 & 0 & 0 & 0 & 0 & 0 & 0 & 0 & 00 & 0 & 0 & 00 & 00 & 3 & 10 & 0 & 13 & 13 \\
\hline 17 & \#cbmce & 0 & 0 & 0 & 0 & 0 & 0 & 0 & 0 & 0 & 00 & 0 & 0 & 0 & $0 \quad 0$ & 3 & 10 & 0 & 13 & 13 \\
\hline 18 & \#ceara & 0 & 0 & 0 & 0 & 0 & 0 & 0 & 0 & 0 & 00 & 0 & 0 & 00 & 0 & 3 & 10 & 0 & 13 & 13 \\
\hline 19 & \#fortaleza & 0 & 0 & 0 & 0 & 0 & 0 & 0 & 0 & 0 & 00 & 0 & 0 & $0 c$ & 0 & 3 & 10 & 0 & 13 & 13 \\
\hline 20 & \#goiás & 3 & 9 & 1 & 13 & 0 & 0 & 0 & 0 & 0 & 00 & 0 & 0 & 00 & 0 & 0 & 0 & 0 & 0 & 13 \\
\hline 21 & \#governodoceara & 0 & 0 & 0 & 0 & 0 & 0 & 0 & 0 & 0 & 00 & 0 & 0 & 0 & 0 & 3 & 10 & 0 & 13 & 13 \\
\hline 22 & \#militar & 0 & 0 & 0 & 0 & 0 & 0 & 0 & 0 & 0 & 00 & 0 & 0 & 0 & 0 & 3 & 10 & 0 & 13 & 13 \\
\hline 23 & \#sspds & 0 & 0 & 0 & 0 & 0 & 0 & 0 & 0 & 0 & 00 & 0 & 0 & 00 & 0 & 3 & 10 & 0 & 13 & 13 \\
\hline 24 & \#stayhome & 0 & 0 & 0 & 0 & 4 & 5 & 3 & 12 & 0 & 00 & 0 & 0 & 0 & 0 & 1 & 0 & 0 & 1 & 13 \\
\hline 25 & \#saúde & 2 & 7 & 1 & 10 & 0 & 1 & 1 & 2 & 0 & 00 & 0 & 0 & 00 & 0 & 0 & 0 & 0 & 0 & 12 \\
\hline 26 & \#coronavirusbrasil & 0 & 0 & 0 & 0 & 0 & 0 & 0 & 0 & 0 & 00 & 0 & 0 & $0 c$ & 0 & 3 & 8 & 0 & 11 & 11 \\
\hline & Total & 40 & 482 & & 544 & 189 & 210 & 115 & 514 & 0 & 02 & 2 & 0 & $17 c$ & 017 & & 136 & 01 & 179 & 1.256 \\
\hline
\end{tabular}

Fonte: elaboração dos autores.

Ao analisar os termos mais utilizados para classificação das postagens em SRSO, segmentadas por Corpos de Bombeiros Militares (Tabela 8), é possível perceber que há uma incidência maior de uso de hashtags por parte dos Corpos de Bombeiros Militares de Santa Catarina (514 ocorrências) e Goiás (544 ocorrências), representando $84,23 \%$ dos 26 termos analisados (valores destacados com o grifo verde na Tabela 8).

O Corpos de Bombeiros Militares de Santa Catarina e de Goiás são exemplos interessantes de uso de termos de classificação nos SRSO: os termos com maior ocorrência classificam o conteúdo informacional veiculado com a localidade e o órgão (no caso de Goiás, utilizando os termos \#cbmgo e \#bombeiro) ou com o assunto e o órgão (no caso de Santa Catarina, utilizando os termos \#cbmsc e \#coronavírus) (valores destacados com o grifo azul na Tabela 8). 


\section{Análise dos documentos oficiais}

Das 20 postagens com vínculo para websites oficiais, quatro foram descartadas, conforme dados e notas da Tabela 4. O Quadro 1 apresenta as principais características dos documentos vinculados a postagens em SRSO, realizados pelo Corpo de Bombeiros Militar do Pará, único a adotar essa estratégia.

Quadro 1 - Características dos documentos vinculados a postagens em Serviços de Redes Sociais Online, realizados pelo Corpo de Bombeiros Militar do Pará

(continua)

\begin{tabular}{|c|c|c|c|c|c|}
\hline$\#$ & $\begin{array}{l}\text { Data de } \\
\text { publicação }\end{array}$ & $\begin{array}{l}\text { Título do } \\
\text { documento }\end{array}$ & $\begin{array}{l}\text { Publicado } \\
\text { por }\end{array}$ & $\begin{array}{l}\text { Tipo de } \\
\text { conteúdo }\end{array}$ & $\begin{array}{l}\text { Vínculo de } \\
2^{\circ} \text { grau? }\end{array}$ \\
\hline 1 & $15 / 05 / 2020$ & $\begin{array}{l}\text { Ações do CBMPA de prevenção e } \\
\text { enfrentamento à Covid-19 }\end{array}$ & $\begin{array}{l}\text { ASCOM } \\
\text { CBMPA }\end{array}$ & Notícia & Não \\
\hline 2 & $15 / 05 / 2020$ & $\begin{array}{l}\text { CBMPA recebe doação de } \\
\text { equipamentos e materiais de } \\
\text { higienização }\end{array}$ & $\begin{array}{l}\text { ASCOM } \\
\text { CBMPA }\end{array}$ & Notícia & Não \\
\hline 3 & $15 / 05 / 2020$ & $\begin{array}{l}\text { CBMPA recebe cestas básicas } \\
\text { para ajudar famílias no } \\
\text { isolamento social }\end{array}$ & $\begin{array}{l}\text { ASCOM } \\
\text { CBMPA }\end{array}$ & Notícia & Não \\
\hline 4 & $28 / 04 / 2020$ & $\begin{array}{l}\text { CBMPA atua em ação de } \\
\text { desinfecção* }\end{array}$ & $\begin{array}{l}\text { ASCOM } \\
\text { CBMPA }\end{array}$ & Notícia & Não \\
\hline 5 & $18 / 04 / 2020$ & $\begin{array}{l}\text { CBMPA orienta sobre medidas } \\
\text { de prevenção à contaminação de } \\
\text { militares* }\end{array}$ & $\begin{array}{l}\text { ASCOM } \\
\text { CBMPA }\end{array}$ & Notícia & $\begin{array}{l}\text { Sim. Três vídeos no YouTube } \\
\text { com instruções sobre a } \\
\text { Covid-19, destinados aos } \\
\text { bombeiros militares do } \\
\text { estado. }\end{array}$ \\
\hline 6 & $10 / 04 / 2020$ & $\begin{array}{l}\text { CBMPA reúne para definir } \\
\text { medidas de ajuste fiscal }\end{array}$ & $\begin{array}{l}\text { ASCOM } \\
\text { CBMPA }\end{array}$ & Notícia & Não \\
\hline 7 & 06/04/2020 & $\begin{array}{l}\text { CBMPA participa da coletiva } \\
\text { sobre o balanço no } 3^{\circ} \text { mês de } \\
2020 \text { da Segurança Pública do } \\
\text { Pará }\end{array}$ & $\begin{array}{l}\text { ASCOM } \\
\text { CBMPA }\end{array}$ & Notícia & Não \\
\hline 8 & $30 / 03 / 2020$ & $\begin{array}{l}\text { CBMPA no apoio aos abrigados } \\
\text { no Mangueirão }\end{array}$ & $\begin{array}{l}\text { ASCOM } \\
\text { CBMPA }\end{array}$ & Notícia & Não \\
\hline 9 & 28/03/2020 & $\begin{array}{l}\text { Prevenção balneária e combate } \\
\text { ao novo coronavírus }\end{array}$ & $\begin{array}{l}\text { ASCOM } \\
\text { CBMPA }\end{array}$ & Notícia & Não \\
\hline 10 & $26 / 03 / 2020$ & $\begin{array}{l}\text { CBMPA orienta o uso seguro do } \\
\text { álcool em gel* }\end{array}$ & $\begin{array}{l}\text { ASCOM } \\
\text { CBMPA }\end{array}$ & Notícia & Não \\
\hline
\end{tabular}




\begin{tabular}{|l|l|l|l|l|l|}
\hline \# & $\begin{array}{l}\text { Data de } \\
\text { publicação }\end{array}$ & $\begin{array}{l}\text { Título do } \\
\text { documento }\end{array}$ & $\begin{array}{l}\text { Publicado } \\
\text { por }\end{array}$ & $\begin{array}{l}\text { Tipo de } \\
\text { conteúdo }\end{array}$ & $\begin{array}{l}\text { Vínculo de } \\
\mathbf{2} \mathbf{O}^{\text {grau? }}\end{array}$ \\
\hline $25 / 03 / 2020$ & $\begin{array}{l}\text { Grupamento Bombeiro Militar de } \\
\text { Altamira realiza campanha de } \\
\text { vacinação contra gripe* }\end{array}$ & $\begin{array}{l}\text { ASCOM } \\
\text { CBMPA }\end{array}$ & Notícia & Não \\
\hline 12 & $18 / 03 / 2020$ & $\begin{array}{l}\text { CBMPA adota medidas } \\
\text { preventivas contra o novo } \\
\text { coronavírus }\end{array}$ & $\begin{array}{l}\text { ASCOM } \\
\text { CBMPA }\end{array}$ & Notícia & $\begin{array}{l}\text { Seín. Vínculo com notícia } \\
\text { (Secretaria da Comunicação) } \\
\text { sobre medidas tomadas } \\
\text { pelo governo do Pará para a } \\
\text { prevenção à covid-19. }\end{array}$ \\
\hline
\end{tabular}

* Publicado no Facebook e no Instagram.

Fonte: elaboração dos autores.

Apesar de o CBMPA apresentar vínculos com documentos oficiais em seu website, essa estratégia foi utilizada apenas nos SRSO Twitter e Facebook. As publicações do Instagram não permitem a criação de hyperlinks com o conteúdo das postagens. Foram identificados 12 documentos, sendo que todos eles foram publicados pela Assessoria de Comunicação no formato de notícia. Apenas dois documentos apresentam relação com outros conteúdos informacionais: um relacionado a três vídeos do YouTube, e outro, a uma notícia veiculada pela Agência Pará (Secretaria da Comunicação) sobre medidas tomadas pelo governo do Pará para a prevenção à covid-19.

Uma nota importante é que, apesar de o Corpo de Bombeiros Militar de Santa Catarina não vincular suas postagens a documentos oficiais, todas as imagens postadas têm uma marca com o endereço eletrônico do website principal, elemento este fora do escopo de análise deste estudo.

\section{CONSIDERAÇÕES FINAIS}

A partir dos dados coletados, é possível perceber que os Corpos de Bombeiros Militares analisados utilizaram os SRSO - Instagram, Facebook e Twitter, elencados em ordem de volume de publicações para compartilhar informações sobre a pandemia da covid-19. O comportamento de adoção dos órgãos a esses serviços corrobora com a literatura da área sobre o papel informativo dos SRSO, especialmente na década de 2010.

Os resultados apontam uma tempestividade por parte dos Corpos de Bombeiros Militares na publicação de informações sobre a covid-19, no início da pandemia, perdendo força no mês de abril de 2020. As publicações foram marcadas com termos classificatórios ligados à temática - genéricos (\#covid e derivações) e específicos (\#fiqueemcasa e derivações) -, além de informações de georreferenciamento (hashtags vinculadas ao estado do Corpo de Bombeiros publicador).

Apesar de esta pesquisa não ter o objetivo de discutir o conteúdo das informações veiculadas, percebese um baixo percentual de publicações ligadas a documentos oficiais que dão suporte às informações divulgadas (5,05\% do total de publicações). A situação se agrava ao se verificar que somente o Corpo de Bombeiros Militar do Pará adotou o procedimento de sempre remeter a mensagem ao documento oficial, já que o conjunto postagem-hyperlink-documento oficial cria um elo que permite uma leitura de um conteúdo 
hipoteticamente mais detalhado ou mesmo apresenta dados que sustentem as informações veiculadas - o que minimiza a crescente onda de notícias falsas.

Outro ponto relevante é que a existência de uma conta institucional nos SRSO não garante que um órgão a esteja utilizando. Por exemplo, os Corpos de Bombeiros Militares dos estados de São Paulo e do Ceará optaram por não publicar conteúdos no SRSO Twitter no período analisado.

Destaca-se que o SRSO Instagram foi o serviço com maior veiculação de informações por parte dos Corpos de Bombeiros Militares, o que acarreta uma dificuldade adicional para a vinculação de documentos fora do serviço, já que a parte textual das postagens não permite o uso de hyperlinks.

Com relação ao quantitativo de postagens dos Corpos de Bombeiros Militares nos SRSO, destacam-se os estados de Goiás, Santa Catarina e Pará, que, juntos, totalizam $83,84 \%$ das postagens no período, o que reforça que não há ligação entre a quantidade de casos de covid-19 e a atuação informativa desses órgãos nesses serviços.

Por meio dos resultados, reforça-se a importância do profissional da informação e das áreas de conhecimento relacionadas, especialmente a Ciência da Informação. A atuação desses profissionais em momentos de crise, como numa pandemia, pode significar uma estratégia mais assertiva para o planejamento, a classificação dos conteúdos a serem veiculados, bem como oferecer meios para mitigar a disseminação de notícias falsas nos SRSO, especialmente ao estabelecer um fluxo informacional com maior granularidade ao cidadão, onde a publicação poderia ser o ponto de acesso a conteúdos produzidos por esses órgãos.

\section{REFERÊNCIAS}

ALEXA. The top 500 sites on the web. [São Francisco]: Alexa Internet, Inc, c2021. Disponível em: https:// www.alexa.com/topsites. Acesso em: 10 mar. 2021.

ALMEIDA, José Maria Fernandes. Breve história da internet. Minho: [s. n.], 2005. Disponível em: https:// repositorium.sdum.uminho.pt/handle/1822/3396. Acesso em: 28 jun. 2021.

BASTOS, Afonso Henrique Sant' Ana. Ordinário marchem: aspectos da militarização do Corpo de Bombeiros do Rio de Janeiro. In: SIMPÓSIO NACIONAL DE HISTÓRIA MILITAR, 1., 26-28 abr. 2016, Rio de Janeiro. Anais [...]. Londrina: Universidade Estadual de Londrina. 2016. Disponível em: https://www.uel.br/cch/his/ ISNHM/index.php?arq=ARQ_anais. Acesso em: 28 jun. 2021.

BRASIL. [Constituição (1988)]. Constituição da República Federativa do Brasil. Brasília (DF): Senado Federal, 2016. Disponível em: https://www2.senado.leg.br/bdsf/bitstream/handle/id/518231/CF88 Livro EC91_2016.pdf. Acesso em: 23 jun. 2021.

BRASIL. Presidência da República. Casa Civil. Lei número 12.527 de 18 de novembro de 2011. Regula o acesso a informações previsto no inciso XXXIII do art. $5^{\circ}$, no inciso II do $\S 3^{\circ}$ do art. 37 e no $\S 2^{\circ}$ do art. 216 da Constituição Federal; altera a lei $n^{\circ}$ 8.112, de 11 de dezembro de 1990; revoga a lei $n^{\circ} 11.111$, de 5 de maio de 2005, e dispositivos da lei $n^{\circ} 8.159$, de 8 de janeiro de 1991; e dá outras providências. Diário Oficial da União, Brasília (DF), p. 1, 18 nov. 2011. Disponível em: http://www.planalto.gov.br/ccivil_03/_ato20112014/2011/lei/l12527.htm. Acesso em: 07 dez. 2021.

BRASIL. Ministério da Saúde. Covid-19 no Brasil. Brasília (DF): Ministério da Saúde, c2021. Disponível em: https://susanalitico.saude.gov.br/extensions/covid-19 html/covid-19 html.html. Acesso em: 12 mar. 2021.

BOYD, Danah. Facebook's privacy trainwreck: exposure, invasion, and social convergence. Convergence: the International Journal of Research into New Media Technologies, [s. I.], v. 14, n. 1, p. 13-20, 1 fev. 2008. Disponível em: https://journals.sagepub.com/doi/10.1177/1354856507084416. Acesso em: 06 dez. 2021.

CALDAS, Wagner Ferreira; MOREIRA, Manoel Palhares. Folksonomia e classificação de etiquetas: estudo de caso Flickr. In: ENCONTRO NACIONAL DE PESQUISA EM CIÊNCIA DA INFORMAÇÃO, 10., 25-28 out. 2009, João Pessoa. Anais [...]. João Pessoa: ANCIB, 2009. p. 1-19. Disponível em: http:/l repositorios.questoesemrede.uff.br/repositorios/bitstream/handle/123456789/62/GT\%202\%20Txt\%2010-\%20 CALDAS\%2c\%20Wagner\%20F..pdf?sequence=1. Acesso em: 08 dez. 2021. 
CASTELLS, Manuel. A sociedade em rede. Traduzido por Roneide Venâncio Majer com colaboração de Klauss Brandini Gerhardt. 8. ed. São Paulo: Paz e Terra, 1999.

CARVALHO, Bruno Leal Pastor de. História pública e redes sociais na internet: elementos iniciais para um debate contemporâneo. Revista Transversos, Rio de Janeiro, v. 7, n. 7, p. 35-53, 2016. DOI: https:// doi.org/10.12957/transversos.2016.25602. Disponível em: https://www.e-publicacoes.uerj.br/index.php/ transversos/article/view/25602. Acesso em: 07 dez. 2021.

CORPO DE BOMBEIROS MILITAR DO CEARÁ. Histórico. Fortaleza: Governo do Estado do Ceará, 2009. Disponível em: https://www.bombeiros.ce.gov.br/2009/01/12/historico. Acesso em: 24 jun. 2021.

CORPO DE BOMBEIROS MILITAR DO ESTADO DE GOIÁS. Histórico. Goiânia: BM/6, 2021. Disponível em: https://www.bombeiros.go.gov.br/sobre-o-cbmgo/historico. Acesso em: 24 jun. 2021.

CORPO DE BOMBEIROS MILITAR SANTA CATARINA. História. Florianópolis: DiTI-DLF, c2021. Disponível em: https://www.cbm.sc.gov.br/index.php/sobre-o-cbmsc/historia. Acesso em: 25 jun. 2021.

CORPO DE BOMBEIROS MILITAR DO PARÁ E COORDENADORIA ESTADUAL DE DEFESA CIVIL. Histórico. Belém: CBMPA, c2021. Disponível em: https://www.bombeiros.pa.gov.br/historico. Acesso em: 24 jun. 2021.

CORPO DE BOMBEIROS SÃO PAULO. Institucional: Planejamento Estratégico do Corpo de Bombeiros. São Paulo: Divisão de Técnologia da Informação e Comunicação, c2021. Disponível em: http://www. corpodebombeiros.sp.gov.br/portalcb/_institucional/. Acesso em: 25 jun. 2021.

FRANCISCHELLI, Raoni de Aguiar. Ações para o fortalecimento da atuação da inspetoria-geral das polícias militares e dos corpos de bombeiros militares frente à crise da segurança pública. 2019. 17f. Trabalho de conclusão de curso (Especialização em Ciência Militares, com ênfase em Gestão Operacional) - Escola de Aperfeiçoamento de Oficiais, Rio de Janeiro, 2019. Disponível em: http://bdex.eb.mil.br/jspuil handle/123456789/4641. Acesso em: 29 jun. 2021.

GOMES, Gabriel Fernandes Chaves Arantes de Carvalho. "Fake news" na saúde pública. 2020. 57 f. Trabalho de conclusão de curso (Graduação em Odontologia) - Universidade de Taubaté, Taubaté. Disponível em: http://repositorio.unitau.br/jspui/handle/20.500.11874/3617. Acesso em: 30 jun. 2021.

FURTADO, Renata Lira; BELLUZZO, Regina Celia Baptista. Gestão do conhecimento e competência em informação: possíveis relações e perspectivas de atuação do profissional arquivista. Informação \& Informação, Londrina, v. 23, n. 2, p. 314-339, 2018. DOI: http://dx.doi.org/10.5433/1981-8920.2018v23n2p314. Disponível em: https://www.uel.br/revistas/uel/index.php/informacao/article/view/28881. Acesso em: 06 dez. 2021.

LUZ NETO, Carlos Felipe da. Marketing de redes sociais: análise comparativa de empresas do segmento de ensino e idiomas. 2017. 88 f. Trabalho de conclusão de curso (graduação Administração) - Universidade Federal do Ceará, Fortaleza, 2017.

MACHADO, Joicemengue Ribeiro; TIJIBOY, Ana Vilma. Redes sociais virtuais: um espaço para efetivação da aprendizagem cooperativa. RENOTE - Revista Novas Tecnologias na Educação, Porto Alegre, v. 3, n. 1, p. 1-9, 2005. DOI: https://doi.org/10.22456/1679-1916.13798. Disponível em: https://seer.ufrgs.br/renote/article/ view/13798. Acesso em: 07 dez. 2021.

NÚCLEO DE INFORMAÇÃO E COORDENAÇÃO DO PONTO BR (ed.). Pesquisa sobre o uso das tecnologias de informação e comunicação nos domicílios brasileiros: TIC Domicílios 2019. São Paulo: Comitê Gestor da Internet no Brasil, 2020. E-book. Disponível em: https://cetic.br/media/docs/ publicacoes/2/20201123121817/tic dom_2019 livro eletronico.pdf. Acesso em: 07 dez. 2021.

OLIVEIRA, Bernard Silva et al. Análise espacial de risco e previsão de casos confirmados do Covid-19 no estado de Goiás. Hygeia - Revista Brasileira de Geografia Médica e da Saúde, Uberlândia, v. 16, p. 348-361, 4 dez. 2020. DOI: http://dx.doi.org/10.14393/Hygeia16056561. Disponível em: http://www.seer.ufu.br/index. php/hygeia/article/view/56561. Acesso em: 28 jun. 2021.

ORGANIZAÇÃO PAN-AMERICANA DA SAÚDE (OPAS). Folha informativa sobre covid-19. Brasilia, DF: Organização Pan-Americana da Saúde, c2021. Disponivel em: https://www.paho.org/pt/covid19. Acesso em: 10 mar. 2021.

RECUERO, Raquel. Redes sociais na internet. 2. ed. Porto Alegre: Editora Sulina, 2014. 
RECUERO, Raquel; SOARES, Felipe. O discurso desinformativo sobre a cura do covid-19 no Twitter: estudo de caso. E-Compós, Brasília (DF), v. 24, p. 1-29, DOI: https://doi.org/10.30962/ec.2127. Disponível em: https:// www.e-compos.org.br/e-compos/article/view/2127. Acesso em: 08 dez. 2021.

RODRIGUES, Fernando de Assis. Coleta de dados em redes sociais: privacidade de dados pessoais no acesso via Application Programming Interface. 2017. 675 f. Tese (Doutorado em Ciência da Informação) Universidade Estadual Paulista, Marília, 2017.

RODRIGUES, Fernando de Assis; SANTANA, Ricardo César Gonçalves. Contextualização de conceitos teóricos no processo de coleta de dados de Redes Sociais On-line. Informação \& Tecnologia, João Pessoa, v. 5, n. 1, p. 18-36, 2018. Disponível em: http://hdl.handle.net/20.500.11959/brapci/110391. Acesso em: 07 dez. 2021.

SASTRE, Angelo; OLIVEIRA, Claudia Silene Pereira de; BELDA, Francisco Rolfsen. A influência do 'filtro bolha' na difusão de fake news nas mídias sociais: reflexões sobre as mudanças nos algoritmos do Facebook. Revista GEMInIS, São Carlos, v. 9, n. 1, p. 4-17, 2018. DOI: https://doi.org/10.4322/2179-1465.0901001. Disponível em: https://www.revistageminis.ufscar.br/index.php/geminis/article/view/366. Acesso em: 06 dez. 2021.

SOUSA JÚNIOR, João Henriques de et al. Da desinformação ao caos: uma análise das fake news frente à pandemia do coronavírus (covid-19) no Brasil. Cadernos de Prospecção, Salvador, v. 13, n. 2, p. 331-346, 2020. DOI: https://doi.org/10.9771/cp.v13i2\%20COVID-19.35978. Disponível em: https://periodicos.ufba.br/ index.php/nit/article/view/35978. Acesso em: 29 jun. 2021.

TEIXEIRA, Vitória Matheus et al. As fake news e suas consequências nocivas à sociedade. In: ENCONTRO VIRTUAL DE DOCUMENTAÇÃO EM SOFTWARE LIVRE, 15.; CONGRESSO INTERNACIONAL DE LINGUAGEM E TECNOLOGIA ON-LINE, 12., 19-21 nov. 2018, Belo Horizonte. Anais [...], Belo Horizonte, v. 7, n. 1, 2018. Disponível em: http://www.periodicos.letras.ufmg.br/index.php/anais linguagem tecnologia/article/ view/15058. Acesso em: 30 jun. 2021.

THEWALL, Mike. Mike Thewall. Wolverhampton: University of Wolverhampton, [2021]. Disponível em: $\underline{\mathrm{http}: / /}$ www.scit.wlv.ac.uk/ cm1993/mycv.html. Acesso em: 19 ago. 2021.

VERMELHO, Sônia Cristina et al. Refletindo sobre as redes sociais digitais. Educação \& sociedade, Campinas, v. 35, n. 126, p. 179-196, 2014. DOI: https://doi.org/10.1590/S0101-73302014000100011. Disponível em: https://www.scielo.br/j/es/a/4JR3vpJqszLSgCZGVr88rYf/abstract/?lang=pt. Acesso em: 07 dez. 2021.

VILELAS, José Manuel da Silva. O novo coronavírus e o risco para a saúde das crianças. Revista LatinoAmericana de Enfermagem, Ribeirão Preto, v. 28, p. e3320, 22 abr. 2020. DOI: https://doi.org/10.1590/15188345.0000.3320. Disponível em: https://www.scielo.br/j/rlae/a/ZnYDYvXXBq6N8jJKpMvLKCb/?lang=en. Acesso em: 29 jun. 2021.

WORLD HEALTH ORGANIZATION (WHO). Timeline: WHO's COVID-19 response. Genebra: WHO, c2021. Disponível em: https://www.who.int/emergencies/diseases/novel-coronavirus-2019/interactive-timeline. Acesso em: 01 mar. 2021.

YANG, Kai-Cheng et al. The covid-19 Infodemic: Twitter versus Facebook. Big Data \& Society, [s. I.], v. 8, n. 1, p. 1-16, 1 jan. 2021. DOI: https://doi.org/10.1177\%2F20539517211013861. Disponível em: https://journals. sagepub.com/doi/10.1177/20539517211013861. Acesso em: 29 jun. 2021. 